intermingled carbonaceous matter have hitherto been dissipated in air. It can be shown that the oil contents of a blackband seam, as well as the ammonia, can be extracted by distillation, and fixed carbon left in intimate association with the ferric oxide, so that the ironstone is in a better condition, both chemically and physically, for treatment in the blast-furnace, leading to a considerable saving of coke, a readier extraction of metal, and less wear-and-tear of the furnace. Mr. Craig boldly faced the economics of the question, and explained in detail the conditions upon which the commercial success of treating the cannels and associated minerals by the method he indicated must depend; and he showed how it compares, as a business proposition, with the well-established Scottish industry.

Dr. Mollwo Perkin contributed a short paper on the relative merits of high- and low-temperature carbonisation, with special reference to the production of fuel-oil; and gave the results of a number of trials with different coals at low temperatures, say $450-55^{\circ}$, showing the very great variation in yield under substantially the same conditions. The average quantity of fuel-oil obtainable from one ton of cannel may be put at 20 gallons. If $\mathrm{I}_{5}, 000$ tons of cannel were carbonised per diem, it would amount to ro5 million gallons of oil per annum, working the plant for $35^{\circ}$ days in the year-no inconsiderable proportion, therefore, of our present needs.

Mr. Berry and Dr. Dunstan dealt more particularly with the chemical and analytical questions involved, such as the modes of sampling the cannel; the determination of the yield of oil; the products of retorting; the chemical nature of cannel oil; effects of temperature on its character; its refining, and fractionation; calorific values and other physical data.

The papers together form a valuable contribution to a subject of special importance at the present time; they serve, moreover, to direct attention to the possibility of a new and permanent British industry, and deserve, therefore, the thoughtful consideration of all who are interested in the development of our national resources.

\section{THE ORGANISATION OF RESEARCH IN AGRICULTURE.}

O $F$ the results of the war, not the least remarkable is the awakening of interest in the application of scientific research to economic objects and the readiness of the State to endow industrial investigations of all kinds; and yet the admitted pre-eminence of Germany in the technical applications of scientific knowledge does not jump to the eyes in the apparatus or operations of war. She cannot even claim priority in her inhumanities. The use of poison-gas was suggested to our War Office soon after the Crimean War and unhesitatingly rejected. Nor has the extraordinarily lavish expenditure of Germany on abstract, as well as industrial, research been productive of very marked new additions to knowledge. The root of the matter must be sought elsewhere. In a paper read by $M$. Georges Wery ${ }^{1}$ at a conference held in Paris last June and presided over by the Minister of Agriculture, one finds attention directed to what is really the dominant characteristic of the German people in relation to this matter-a characteristic to which much of their recent advance in efficiency may be ascribed.

The German people, as a whole, believe in the economic value of knowledge, respect the scientific method, are eager to give practical effect to the results attained by that method, and, as a result, are ready to submit their industries to scientific direction. It will avail us little to endow scientific research unless scientific knowledge is deferred to more than it has been in the past. The fond belief that scientific results can be ordered and paid for like goods, and that the knowledge which gave these results birth has no continuing industrial value, must be abandoned, if we set out to compete with the German in his own field. The attitude of the public generally, and particularly that of the leaders of industry, must change.

The main purpose of M. Wery's paper is to give an account of the organisation of research in agriculture in foreign countries, and to contrast the comparatively meagre provision made in France for this object with that made in Germany and America. He points out that Germany has no fewer than ninety-nine institutions, comprising 162 distinct laboratories, devoted to research in agricultural subjects, all of which are in receipt of State subventions. Prussia alone has fifty-eight institutions of this nature, all of which have large staffs, "luxurious" laboratories, and ample equipment. As evidence of the hold which scientific work has gained on the German agriculturist, M. Wery cites the remarkable fact that some years ago the German farmers and landowners raised a sum of a million and a half sterling, which they presented to the Emperor for the purpose of foundins industrial and agricultural laboratories. No better evidence could be given of the fundamental difference between the attitude of the German agriclilturist to science and that taken up by the English farmer. The gross revenue of the agricultural research stations in Germany approaches $400,000 l$. - a sum which M. Wery effectively contrasts with the parallel figure in France of $60,000 l$. he might have added the corresponding English figure, which is less than $40,000 l$ ! But even the German figure pales before the American total of $\mathrm{r}, \mathrm{0o0}, \mathrm{oool}$.

It is pointed out that the German organisation of research was not without what may be termed a publicity value in the past. The admiration which it excited, if not calculated to assist the sale of German goods, at any rate led to the exploitation of German "Kultur " in England and created a demand for the German savant outside his own country-results which, no doubt, were indirectly of economic value to the Fatherland. M. Wery is on sure ground when he proceeds to

1 Bulletin de la Société d'Encouragenent pour l'Industrie Nationale No. 5 , 1017.

NO. 2522 , VOL. IOO] 
dwell on the limitations of German scientific work in its useless elaboration of details, its devotion to the accumulation of mere data, and its purely material objects and results; and when he claims for France a greater number of discoveries of the first rank, a greater love of knowledge for its own sake, we can heartily agree. "The bright sunlight," he says characteristically, "which illumines the footsteps of Descartes, Lavoisier, and Pasteur will indeed be obscured, if the fogs which rise from the plains of Germany come our way."

We may also quote the author's plea for a minimum of State interference. "Discoveries," he says, "are not made by the stroke of a magician's wand. L'esprit souffle ou il veut. What the State should provide for the savant is the means for research. It should not impose methods or predetermined ideas; otherwise all initiative will be stifled." We may join with M. Wery in hoping that his plea in the interests of the extension of scientific research in agriculture in France will prove successful. The country which produced a Boussingault and a Pasteur must not be suffered to lag behind.

\section{NOTES.}

In the course of his statement on the Army Estimates, in the House of Commons on February 20, Mr. Macpherson directed attention to the health of the troops in the various theatres of war. In the Napoleonic campaigns 97 per cent. of the total deaths were from disease and only 3 per cent. were on the battlefield. In the South African campaign 67,000 cases of disease were admitted into hospital, of whom more than 8000 died. In France up to November last the deaths from disease were only one-fourth of the number that died from the same cause in South Africa. In Macedonia conditions are not so satisfactory, but as a result of the hygienic measures taken the amount of sickness in I9I7 was reduced to two-thirds, and the death-rate to one-third, of what it was in I9I6. A well-deserved tribute was paid to the Army Medical Service and to the services which had been rendered by the retiring Director-General, Sir Alfred Keogh.

Dr. Fleming Sandwith, C.M.G., died suddenly and unexpectedly on February 17 . He was in his sixtyfourth year, and had been invalided home after two strenuous years in Egypt. Few civilian medical men could show such a record of military service. He had worked in the Turko-Serbian war of 1876 , and in the Russo-Turkish war in the following years. He had been on Baker Pasha's staff, and was senior physician to the Imperial Yeomanry Hospital in the South African war. In December, I9I5, he was appointed temporary colonel in the Royal Army Medical Service, and proceeded to Egypt, a country well known to him, for in $188_{3}$ he was appointed for preventive work there against cholera. In Egypt Dr. Sandwith remained many years engaged in sanitary work and private practice, acquiring a considerable reputation in tropical medicine. After the South African war he settled in London, and became lecturer in tropical diseases to St. Thomas's Hospital, physician to the Seamen's Branch Hospital, Albert Dock, and lecturer in the School of Tropical Medicine there. He was also Gresham professor of physic, and his lectures on such subjects as plague, Pasteur's life and work, insect carriers of disease, etc., were deservedly popular. A man of genial and kindly disposition, Dr. Sandwith will be missed by a wide circle of patients and acquaintances.

The Minister of Reconstruction, Dr. Addison, has appointed an Advisory Council to assist him in considering the many proposals that come before his Department for review. The work of the Council is to be discharged through four sections, each of which will advise the Minister on specific questions referred to it by him within the general subjects allocated to the several sections, namely :-Section I. : Finance, transport, and common services; Section II. : Production and commercial organisation; Section III. : Labour and industrial organisation; Section IV.: Social development (including rural reconstruction). The Council at presents consists of thirty-seven members, among whom are the following:-Mr. C. R. Wr Adeane, late president, Royal Agricultural Society; Sir Richard Glazebrook, director of the National Physical Laboratory; Mr. H. J. Mackinder; the Hon. E. G. Strutt, an authority on agricultural questions; and Prof. T. B. Wood, professor of agriculture, Cambridge University. Mr. Eustace Davies, of the Ministry of Reconstruction, has been appointed secretary to the Advisory Council. It is noteworthy that while engineering, agriculture, industry, labour, the law, finance, and politics all have their representatives, pure and applied science, other than engineering and agriculture, is represented by one member only. Presumably Section IV. will be concerned with such problems as the welfare of workers and housing for the people, yet there is not a single member representing medicine and hygiene or architecture.

Sir G. Cave announced, in the House of Commons on February 20, that for the present year summer-time will be brought into force on the morning of Sunday, March 24, and will continue until the night of Sunday, September 29 , an arrangement that will give an additional five weeks of summer-time this year. $\mathrm{He}$ added :--"As regards the suggestion that during the midsummer period the time should be advanced by an additional hour, there is no power under the statute to make this further change, and I may add that the Committee which had the proposal before them reported unanimously against it." The agricultural correspondent of the Times points out in Tuesday's issue, what we urged on many occasions when the "daylight saving" principle was under discussion, namely, that agricultural interests were ignored by it. Referring to the introduction of summer-time in the fourth week of March, he remarks :- "The drawback is that much of the early morning work at the homestead-the grooming and feeding of horses, the feeding and milking of cows, and the dispatching of the milk-will have to be done by artificial light, which means additional expense, and the prolongation of the period of dark mornings makes the farm less attractive for those whom it employs. The dairy farmer is especially affected, and there are cases in which milk production has been abandoned chiefly because of the labour trouble arising from the operation of the Daylight Saving Act. The most serious disadvantages suffered by the farmer, however, occur from June onwards. The early dews that are no great hindrance at seedtime are a definite hindrance to progress when the work of saving the crops begins. From the time when haymaking is begun in June until the last of the cereals is gathered in September or later, an hour in the late afternoon is often worth two in the morning; yet the farmer finds himself compelled to make good at the cost of overtime the hour that has been deducted from the morning of his normal day. Because of the adNO. 2522 , VOL. IOO] 